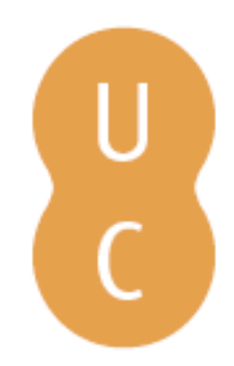

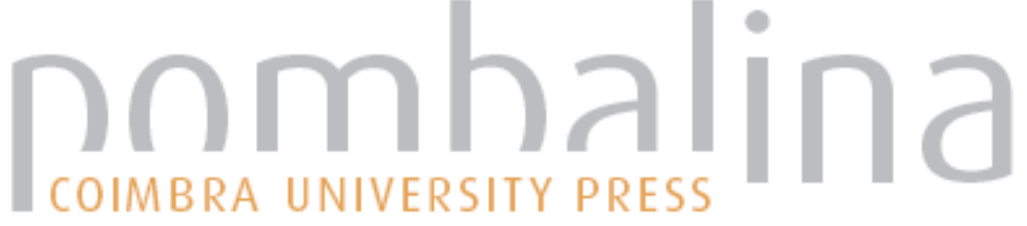

\section{Uma visão biofísica do stress em sistemas vivos}

Autor(es): Quintanilha, Alexandre

Publicado por: Imprensa da Universidade de Coimbra; Gradiva

URL

persistente:

URI:http://hdl.handle.net/10316.2/32682

DOI:

DOI:http://dx.doi.org/10.14195/978-989-26-0389-6_12

Accessed : $\quad$ 26-Apr-2023 10:48:41

A navegação consulta e descarregamento dos títulos inseridos nas Bibliotecas Digitais UC Digitalis, UC Pombalina e UC Impactum, pressupõem a aceitação plena e sem reservas dos Termos e Condições de Uso destas Bibliotecas Digitais, disponíveis em https://digitalis.uc.pt/pt-pt/termos.

Conforme exposto nos referidos Termos e Condições de Uso, o descarregamento de títulos de acesso restrito requer uma licença válida de autorização devendo o utilizador aceder ao(s) documento(s) a partir de um endereço de IP da instituição detentora da supramencionada licença.

Ao utilizador é apenas permitido o descarregamento para uso pessoal, pelo que o emprego do(s) título(s) descarregado(s) para outro fim, designadamente comercial, carece de autorização do respetivo autor ou editor da obra.

Na medida em que todas as obras da UC Digitalis se encontram protegidas pelo Código do Direito de Autor e Direitos Conexos e demais legislação aplicável, toda a cópia, parcial ou total, deste documento, nos casos em que é legalmente admitida, deverá conter ou fazer-se acompanhar por este aviso.

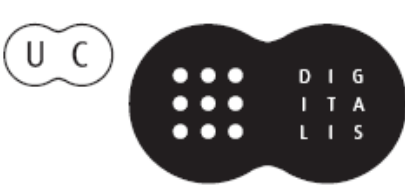


C I E N C I A I B E R T A

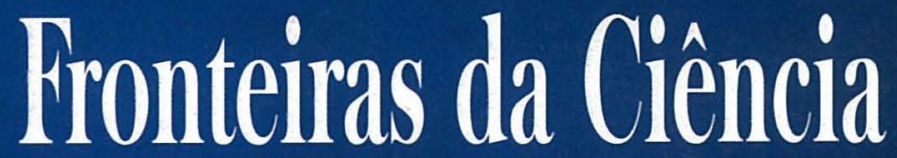

Desenvolvimentos Recentes - Desafios Futuros

RUI FAUSTO • CARLOS FIOLHAIS • JOÃO FILPE QUURRÓ

Coordenadores

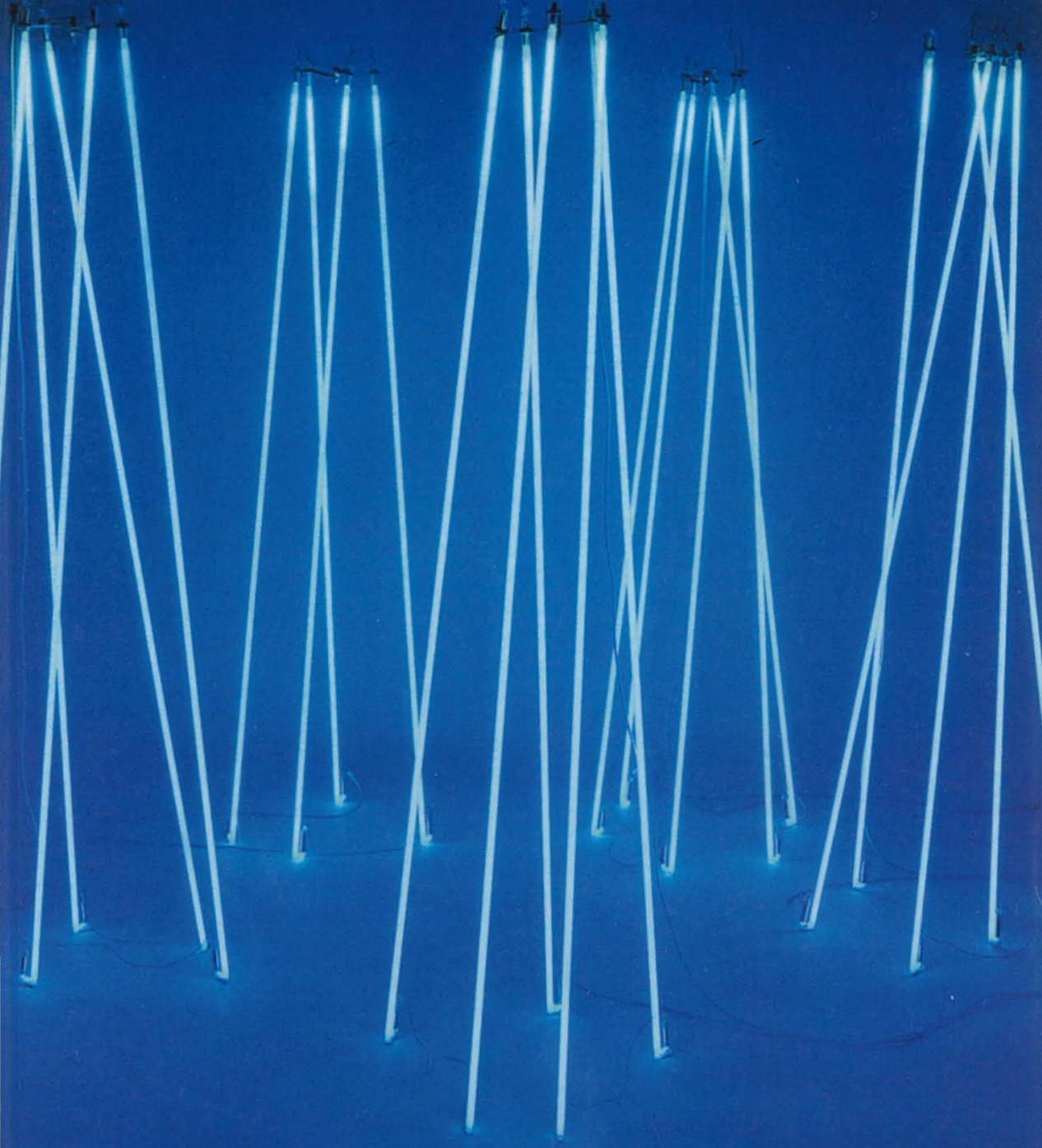

gradiva - Imprensa da Universidade de Coimbra 
(Página deixada propositadamente em branco) 


\section{RUI FAUSTO, CARLOS FIOLHAIS JOÃO FILIPE QUEIRÓ \\ Coordenadores}
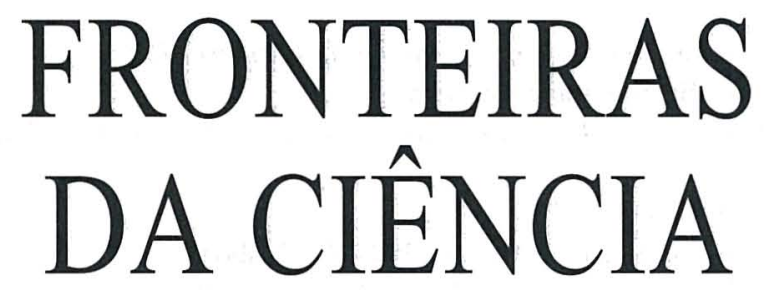

Desenvolvimentos Recentes Desafios Futuros 
(C) Gradiva - Publicações, L. da / Imprensa da Universidade de Coimbra, 2003 Coordenação editorial: Rui Fausto, Carlos Fiolhais e João Filipe Queiró Tradução: Jean Burrows, Vivien Burrows, Rui Fausto, Carlos Fiolhais e João Filipe Queiró

Revisão do texto: Isabel Pedrome

Capa: António Barros [Imprensa da Universidade. Coimbra], sobre imagem de «Águas Vivas», escultura de Silvestre Pestana, 2001

Foto: António Alves; Infografia: ESTÍMULUS [design]; Cortesia: Galeria Alvarez-Arte Contemporânea

Paginação: António Resende e Paula Isabel Jorge

Impressão e acabamento: G.C. - Gráfica de Coimbra, L. ${ }^{d a}$

Reservados os direitos para Portugal por:

Gradiva - Publicações, L. ${ }^{\text {da }}$ e Imprensa da Universidade de Coimbra

Gradiva - Publicações, L.da

Rua Almeida e Sousa, 21, r/c, esq.•1399-041 Lisboa

Telefs. $213974067 / 8 \cdot 213971357 \cdot 213953470$

Fax $213953471 \cdot$ Email: gradiva@ip.pt

URL: http://www.gradiva.pt

Imprensa da Universidade de Coimbra

Rua Antero de Quental, 195 • 3000-033 Coimbra

Telefs. 351239853110

Fax 3512398531 19・e-mail: fjrpress@ci.uc.pt

URL: http://www.imp.uc.pt

ISBN: 972-662-923-3

1." edição: Agosto de 2003

Depósito legal n. ${ }^{\circ} 199$ 463/2003 
Alexandre Quintanilha

Instituto de Ciências Biomédicas Abel Salazar e

Instituto de Biologia Molecular e Celular

Universidade do Porto

\section{Uma visão biofísica do stress em sistemas vivos}

Foi difícil pensar num tópico suficientemente geral para interessar uma audiência multidisciplinar e, apesar disso, não tão geral que pudesse ser considerado superficial. Quando me decidi a falar sobre o stress, pensei que seria importante, antes de tudo, tornar muito claro o que entendo por stress, uma vez que o termo é associado geralmente ao stress psicológico. Não sei nada sobre o cérebro, e portanto o stress de que vos vou falar é stress físico e fisiológico em vários sistemas.

A maior parte do trabalho que vos vou expor foi efectuado tanto em animais como em seres humanos. Trata-se essencialmente de um sumário de tópicos diferentes que me interessaram ao longo dos últimos vinte anos. E vou começar com um tipo de stress muito comum, mas que talvez não seja bem compreendido, excepto por aqueles que trabalham em áreas relacionadas com ele: o stress do oxigénio. Adiante discutirei outros tipos de stress que afectam os sistemas vivos.

Começo com as características da Terra quando ela não albergava nenhumas criaturas vivas e em particular quando não existia fotossíntese. As características da Terra estariam provavelmente entre as dos planetas Mercúrio e Vénus. A temperatura na superfície da Terra seria da ordem de $300{ }^{\circ} \mathrm{C}$ e as pressões de 60 bar. Se a vida nunca tivesse evoluído à superfície da Terra, este seria o ambiente característico do nosso planeta. 
Logo que a fotossíntese surgiu, há aproximadamente 2,5 a $3 \mathrm{mil}$ milhões de anos, a concentração de $\mathrm{CO}_{2}$ diminuiu dramaticamente para níveis muito baixos e a concentração de oxigénio aumentou também dramaticamente cerca de $20 \%-21 \%$. Isto foi o suficiente para a temperatura média da Terra baixar para $13{ }^{\circ} \mathrm{C}$ e para a pressão descer para cerca de 1 bar. Tal significa que a mudança que ocorreu há 3 mil milhões de anos foi fundamental para permitir a evolução de um grande número de novas estruturas biológicas complexas à superfície da Terra. Mas, como em tudo na vida, teve de se pagar um preço e o preço foi o oxigénio que, como é bem sabido, é perigoso para os sistemas vivos.

Todos se lembram, provavelmente da escola secundária, de que o oxigénio é a principal substância usada pelos organismos aeróbicos para produzir grandes quantidades de ATP, a forma principal de energia nas células, e que foi o oxigénio que permitiu a evolução para estruturas vivas mais complexas, em particular as que se desenvolveram na superfície terrestre e não nos oceanos. O oxigénio apareceu, como disse, há 2,5 a 3 mil milhões de anos. Outra das consequências do aparecimento do oxigénio de que não estamos muito cientes é ele ter permitido a evolução do ozono na estratosfera. E, como sabem, esta é uma etapa muito importante na evolução da Terra porque protegeu os organismos que estavam na superfície do planeta dos efeitos prejudiciais das radiações ultravioletas. Permitiu que os organismos saíssem dos oceanos sem sofrerem os efeitos prejudiciais do ozono.

Mas à medida que o oxigénio aumentava duas coisas aconteceram: alguns organismos retrocederam, movendo-se dos lugares onde estava $o$ oxigénio para ambientes anaeróbicos nas profundezas dos oceanos. Outros adaptaram-se rapidamente para poderem sobreviver, tendo desenvolvido mecanismos de defesa relativamente ao oxigénio.

Mas que história é esta da toxicidade do oxigénio? O que quero dizer quando afirmo que o oxigénio é tóxico? Todos sabem que a maior parte dos metais oxidam ao ar livre. As superfícies metálicas enferrujam. As pontes, a menos que se lhe renove a pintura e se lhes dê o devido tratamento, oxidam, enferrujam. Se tivermos um material biológico qualquer, como por exemplo a manteiga ou o leite, eles rançam, e parte desse mecanismo é a oxidação dos componentes do leite ou da manteiga. E nós não somos muito diferentes, uma vez que as nossas células têm mecanismos muito semelhantes aos que ocorrem noutras formas da natureza. De facto, algumas pessoas pensam que envelhecer é justamente uma outra forma de rançar, de modo que toda a gente perde a juventude e se torna cada vez mais rançosa! 
Isto era bem sabido em Inglaterra e em França por Priestley e por Lavoisier, a quem a descoberta do oxigénio é geralmente atribuída. De facto, foi Scheele, na Suécia, a primeira pessoa a discutir as propriedades do gás que mais tarde foi chamado oxigénio.

No entanto, o facto de o oxigénio ser um gás venenoso, e portanto perigoso, só foi discutido em pormenor cerca de um século mais tarde, por Paul Bert, tendo este fornecido em favor disso um grande conjunto de provas. As pessoas sabiam que o oxigénio era tóxico, sabiam que se colocassem um pequeno rato numa atmosfera com oxigénio a $100 \%$ ele entrava em convulsões e morria, mas foi somente Paul Bert quem colocou realmente este facto num quadro científico. Curiosamente foi Julio Verne quem popularizou a ideia de que o oxigénio é um gás venenoso, muito, muito mais tarde. Todos sabiam que o oxigénio era tóxico, mas foi Rebecca Gershman, uma cientista argentina, quem, duzentos anos mais tarde, descreveu pela primeira vez, num artigo da Science, os mecanismos responsáveis pela toxicidade do oxigénio. Muitos anos decorreram entre a descoberta do gás, a descoberta de que ele era venenoso apesar de precisarmos dele para viver e a descrição do mecanismo da toxicidade. Eis uma história interessante, neste campo particular, da evolução da ciência.

Que o oxigénio é venenoso é hoje um facto bem estabelecido. Eu tenho muitos exemplos para vos dar, mas apresento-vos apenas um. Considerem a sobrevivência de células em cultura, células de ovários de ratos, à medida que são irradiadas por doses crescentes de radiação ionizante. Como é de esperar, a radiação é prejudicial, de modo que as células irradiadas vão morrer, decrescendo a sua taxa de sobrevivência com o tempo de exposição. Como é também de esperar, a velocidade a que morrem torna-se cada vez maior à medida que se aumenta a concentração de oxigénio no tecido.

Conhecemos este facto desde há bastante tempo e, realmente, esta é uma das razões por que o tratamento por radiação de tumores é um problema complicado: no interior de um tumor há muito menos oxigénio do que nos tecidos circunvizinhos. Quando se irradiam tumores podem causar-se mais danos às células em torno do tumor do que às suas células, pelo que são necessários mecanismos para focar esta radiação na zona exacta onde este está localizado.

Há muitos exemplos deste tipo de danos. Outra observação com a qual muitos dos presentes estão familiarizados, uma vez que a maioria deve ter avós ainda vivos, é que à medida que as pessoas envelhecem lhes aparecem manchas pigmentadas nas costas das mãos e dos braços. Os que são muito novos provavelmente não têm ainda essas manchas mas quando ficarem mais velhos verão que elas se acumulam; as 
manchas são realmente produtos danificados da oxidação de proteínas, lípidos, $\mathrm{ADN}$, que se acumulam porque os mecanismos de reparação e depuração não são tão eficientes como na juventude. E, embora a pele seja aquilo que melhor se vê, de facto muitos tecidos, incluindo o cérebro, vão também acumulando estes produtos.

Convém recordar-vos um outro exemplo da toxicidade do oxigénio. Este relaciona-se com a sobrevivência dos ratos em função da pressão do oxigénio. À medida que aumentamos a pressão do oxigénio, a taxa de sobrevivência destes animais diminui, justamente como seria de esperar para um gás venenoso como o oxigénio. A experiência pode fazer-se com pressões elevadas ou com concentrações maiores de oxigénio. Se se ultrapassar a concentração de $20 \%$, que normalmente respiramos, até $40 \%$ e a seguir até $60 \%$, observam-se cada vez mais danos.

Agora a nossa história. O oxigénio que encontramos na nossa atmosfera é produzido pelo processo da fotossíntese. $95 \%$ do oxigénio que os mamíferos, incluindo o homem, consomem participa numa reacção que é o oposto exacto da fotossíntese, nomeadamente a respiração. Assim, o oxigénio é usado por todos nós principalmente para produzir ATP. Mas há muitos outros mecanismos onde o oxigénio é consumido: temos o oxigénio usado em mecanismos de desintoxicação no fígado, nomeadamente a cafeína que bebemos todas as manhãs, o álcool que ingerimos, ou os comprimidos de parecetamol para as nossas dores de cabeça. Todos os tipos de compostos interessantes que regulam a função do nosso músculo liso (que é o músculo que não está sob controlo voluntário), como as prostaglandinas, prostaciclinas, etc, são também produzidos por mecanismos consumidores de oxigénio.

Finalmente um outro exemplo sobre o qual voltarei a falar, que é o facto de a biologia ser muito inteligente (quase por acidente, diria eu). Uma vez que os sistemas biológicos sabem que o oxigénio é tóxico, decidiram usá-lo para seu próprio benefício. Assim, a maioria dos glóbulos brancos do sangue, que correm por todo o nosso corpo e são responsáveis pela defesa relativamente aos micro organismos que nos invadem, usam um mecanismo de defesa e destruição que também consome oxigénio. Quando um glóbulo branco ataca uma bactéria, usa como mecanismo químico de destruição a produção de muitos tipos de moléculas muito oxidantes, partindo do próprio oxigénio. Estes glóbulos brancos aprenderam o modo de usar as propriedades tóxicas do oxigénio para combater e destruir os micro organismos que invadem o corpo.

Logo que entre qualquer coisa de estranho no nosso corpo, qualquer coisa que entra no plasma do sangue mas não deve lá estar, os glóbulos brancos tentam removê-lo. Ao tentarem remover o que é estranho geram 
espécies reactivas de oxigénio (moléculas oxidante) e libertam vários tipos de proteases diferentes, isto é, de enzimas que quebram proteínas. Mas, uma vez que mesmo os sistemas biológicos não são $100 \%$ perfeitos, todos aqueles mecanismos destruirão mais que as bactérias invasoras: destruirão também alguns dos tecidos nos vasos sanguíneos onde estão os glóbulos brancos. Assim, quando uma pessoa se protege de uma invasão de corpos estranhos, também sofre alguns danos nos tecidos em redor, o que não é nenhuma surpresa. Se nos cortarmos, se tivermos uma ferida que fique infectada, produz-se algum pus, que é formado basicamente pelos glóbulos brancos que morrem na batalha contra as bactérias. Mas num corte pequeno infectado encontra-se um pouco de pus e tecido vermelho a toda a volta; esse vermelho tem a ver com o facto de estes glóbulos brancos, ao destruírem as bactérias, danificaram também um pequeno pedaço dos tecidos em volta.

Vou agora escolher três exemplos em que o meu grupo tem trabalhado e onde é provável que ocorra este tipo de danos. E os exemplos que escolho são muito vulgares - escolho-os precisamente porque são comuns, porque se fala deles na vida diária - e eu gostaria de relatar abreviadamente qual o ponto onde estamos agora na história que lentamente vamos escrevendo.

Os exemplos que escolhi relativos ao stress são três. O primeiro de que vou falar é o exercício. Ora quando fazemos um exercício árduo danificamos as nossas células. O exercício em níveis moderados é obviamente uma coisa boa, uma vez que ao fazê-lo podemos aumentar os mecanismos de defesa contra algo que se tornará claro mais adiante. Quando nos exercitamos muito arduamente e não estamos habituados a isso, tal como eu, no dia seguinte mal podemos andar, os nossos pés estão doridos e, se fizermos algumas flexões (que eu, felizmente, nunca faço), os braços ficam doridos. É bem sabido que, se fizermos exercício arduamente e não estivermos bem treinados para isso, danificamos os nossos músculos e talvez também vários órgãos.

De facto, o exercício é um modelo muito bom para estudar o stress, e o stress oxidativo em particular, porque, como é sabido, quando se faz exercício consome-se muito mais oxigénio; quando fazemos exercício podemos consumir dez vezes mais oxigénio do que quando dormimos. Assim, é natural perguntar: se consumimos mais oxigénio, estaremos a causar danos durante o exercício? Este é o primeiro exemplo de que queria falar.

O segundo, que é também muito comum, nomeadamente entre as mulheres, é a gravidez. A gravidez, um estado que as mulheres experimentam ocasionalmente, é uma situação onde há stress. E é muito fácil 
compreender porque há stress: o feto é geneticamente diferente da mãe, e sabemos que, se pusermos um órgão num corpo geneticamente diferente, ele será rejeitado. Mas então porque não é o feto excluído (grande ponto de interrogação)? Apesar de ser geneticamente diferente da mãe (metade dos cromossomas vem do pai), por que razão não é excluído? Há teorias e dados muito interessantes sobre isto. Mas o que quero mostrar-vos é que, de facto, está bem provado que durante a gravidez o estado de stress não é contínuo e que, felizmente, é muito bem regulado. Quando deixa de ser bem regulado (no fim da gravidez), inicia-se algo chamado eclampsia ou pré-eclampsia, em que a criança pode ser perdida e a mãe também pode morrer. Assim, a gravidez é um exemplo muito bom de aumento do stress.

E, finalmente, o último exemplo é a arteroesclerose, de que muitos (entre os quais eu próprio!), à medida que forem envelhecendo, acabarão provavelmente por sofrer. A arteroesclerose é, como sabemos, uma espécie de inflamação de nível muito baixo dos vossos vasos sanguíneos. Permanece frequentemente num nível muito baixo e é muito difícil para alguém prever em que altura se vai produzir um acontecimento que vai danificar o coração ou o cérebro. Estes são os três exemplos de que quero falar.

Começo com o exercício. Mas em primeiro lugar quero descrever o que são, de facto, os mecanismos de defesa contra muitas destas espécies oxidantes. Disse já que o oxigénio consumido na vida diária é usado antes de mais para gerar ATP. Quando o oxigénio se reduz a água, usamos o $\mathrm{NADH}$, que é um agente redutor produzido nas células; tudo isto ocorre nas mitocôndrias das células. As mitocôndrias são as pequenas «pilhas» de todas as células. Uma vez que as mitocôndrias não são inteiramente perfeitas, de vez em quando os electrões redutores, em vez de reduzirem o oxigénio, são desviados e produzem superóxido, que é uma das espécies oxidantes produzida pelos glóbulos brancos do sangue. O superóxido é um componente oxidante muito forte que pode ser gerado do oxigénio.

Poderia estar duas horas a falar-vos da química do oxigénio, mas não quero fazê-lo; quero dizer apenas que temos felizmente muitos mecanismos nas nossas células para nos proteger do stress oxidativo. De facto, a razão por que se diz que devemos comer frutas e vegetais é que estas têm grandes quantidades de vitaminas $\mathrm{E}, \mathrm{C}$ e caroteno. Estes são os compostos nas células que nos protegem contra os danos oxidantes e que repararão quase todos os que forem produzidos durante um ataque oxidante. Estes constituem, como costumo dizer, uma espécie de «amortecedor» para não ficarmos «rançosos» - não ficamos rapidamente «rançosos» porque possuímos estas substâncias no nosso corpo. De facto, quando formos mais velhos, não apenas as nossas mitocôndrias se tornarão menos 
eficientes e produzirão mais espécies radicais oxidantes, como diminuirá a concentração destes compostos anti-oxidantes. É por isso que à medida que envelhecemos a «relação» entre a nossa protecção e os nossos danos diminui, acelerando assim o envelhecimento.

Um outro protector muito importante contra os danos da oxidação é a glutationa. Este é um composto químico muito simples que existe em grandes concentrações nas células. Tem um grupo redutor SH muito importante. Sempre que o stress oxidativo aumenta, alguma desta glutationa é usada para reparar alguns dos aminoácidos da proteína que forem oxidados. A glutationa fica oxidada neste processo.

Em 1978, quando começámos os nossos trabalhos sobre o stress no exercício, muita gente sabia que as concentrações elevadas e altas pressões de oxigénio eram perigosas. Ninguém sabia era se os danos oxidantes seriam afectados por taxas elevadas de consumo de oxigénio. A razão por que escolhemos o exercício como modelo foi que no exercício se pode, em algumas criaturas, aumentar a taxa do consumo de oxigénio quase 300 vezes.

Uma das primeiras coisas que fizemos foi verificar o que acontecia aos níveis de glutationa dentro dos vários órgãos de animais (ratos) e encontrámos algo bem curioso.

Uma das primeiras coisas que observámos foi que, de facto, existe quase uma diminuição linear dos níveis de glutationa no fígado com o tempo de corrida. Mas isto intrigou-nos; por que razão experimentaria o fígado qualquer tipo de danos de tipo oxidante durante a corrida? O fígado não faz nenhum exercício, os músculos é que fazem o exercício durante uma corrida! Assim por que haveria uma diminuição do nível de glutationa no fígado durante o exercício? Não compreendíamos porquê, mas mostrámos duas coisas: os animais mais novos não só perdem a glutationa a uma taxa muito mais lenta do que os animais mais velhos, mas também, se pegarmos em animais mais velhos e os treinarmos um pouco todos os dias, após três meses, quando os obrigamos a correr, eles começam a comportar-se como animais novos.

Isto significa que há uma adaptação durante o exercício regular que faz o sistema tornar-se mais eficiente a usar a glutationa. Esta era a primeira evidência de que um bocadinho de stress diário pode realmente beneficiar alguém, porque desenvolve os sistemas que poderão depois enfrentar melhor um stress árduo.

Mas nós estávamos ainda intrigados pelo facto de o fígado ter uma diminuição tão incrível de níveis de glutationa durante o exercício. E então olhámos para o músculo; de facto, olhámos em primeiro lugar para o músculo e só depois para o fígado. O músculo era muito estranho - no músculo não havia absolutamente nenhuma mudança nos níveis de 
glutationa durante a corrida prolongada. Tínhamos aqui um grande enigma. O músculo fazia todo o exercício, consumia todo o oxigénio e não sofria nenhuma mudança nos seus níveis de glutationa. Porquê? só mais tarde viemos a compreendê-lo. De facto, o fígado é o principal produtor de glutationa e, durante o exercício, despeja no plasma glutationa que é consumida pelo músculo para se manter protegido enquanto o fígado permanece com níveis baixos desta substância. $\mathrm{E}$ o facto de o fígado lançar glutationa no plasma, que é depois recebido pelo músculo, revela-se nos níveis da substância no plasma. Mas há uma consequência interessante deste facto que eu uso para arreliar todos os meus amigos que fazem muito exercício! É que a maioria das pessoas que fazem exercícios pesados, como por exemplo ténis, ou squash, que é ainda mais pesado, quando terminam o seu exercício, sentam-se e bebem um grande copo da sua bebida alcoólica preferida. Deixem-me apenas adverti-los de que devem ser um pouco mais cuidadosos com o consumo de álcool depois de exercícios pesados, porque o fígado está numa condição muito mais frágil para combater a toxidade do álcool do que antes.

Por volta da mesma altura (1981), Helmut Sies, que é bem conhecido pelas pessoas que trabalham no stress oxidativo, mostrou que há determinadas hormonas que levam o fígado a despejar a glutationa no plasma. Uma delas é a vasopressina, um regulador osmótico do controlo da água no corpo. A vasopressina in vitro num fígado perfusado fará o fígado despejar a glutationa no plasma.

Ora a vasopressina é a primeira a subir durante o exercício, e assim obtemos uma explicação satisfatória para o facto de, durante o exercício, haver um método fisiologicamente controlado para obrigar o fígado a despejar para o plasma uma substância (glutationa) que é necessária para proteger o músculo - uma história muito bonita! Em 1895, Kaplowitz, um cientista muito conhecido pelo seu trabalho com a glutationa, sugeriu que o fígado era realmente a fonte principal da glutationa, que era carregada pelo sangue e distribuída depois aos rins e aos intestinos. Não tinha a certeza sobre os pulmões. Nós adicionámos os músculos à lista de órgãos que recebem glutationa.

Só para terminar a história da glutationa: se se retirar a glutationa do fígado, são necessárias muitas horas, ou talvez mesmo dias até que os níveis de glutationa regressem aos níveis normais. Assim, mesmo que terminemos um exercício, por exemplo ténis, às quatro horas da tarde, provavelmente não teremos ainda suficiente glutationa no fígado durante várias horas. Assim, não vale a pena esperar algumas horas para beber um uísque, devemos esperar alguns dias, ou pelo menos um dia para nos metermos nos copos... 
A outra coisa de que queria falar é da adaptação que ocorre quando nos exercitamos regularmente. Do que eu disse segue-se que, quando nos exercitamos, é de esperar que alguma glutationa fique oxidada. Os níveis da glutationa oxidada no plasma são muito mais elevados depois de o exercício ter terminado. Contudo, nos animais treinados, mesmo depois de terem corrido 400 minutos, quando comparados com animais não treinados depois de estes terem corrido algo como 95 minutos, os níveis de glutationa oxidada no plasma são sempre mais baixos. Claramente, obtém-se pelo treino uma melhoria na maneira como a glutationa recircula, se o treino for feito de forma progressiva.

Isto significa provavelmente que aqueles que treinam mais regularmente podem provavelmente permitir-se beber um pouco mais de uísque do que aqueles que não treinam regularmente e vão fazer algum exercício pesado. Esta é uma das primeiras mensagens que tenho para transmitir.

Agora, por que razão afirmei que os glóbulos brancos eram as células que protegem contra as substâncias estranhas? Bem, ocorreu-nos que, quando alguém faz exercícios pesados, talvez se danifiquem algumas células. E para onde vão os pedacinhos de células danificadas? Entram no nosso sangue...

Assim, pareceu-nos razoável que, se tivermos no sangue estes pedacinhos de células degradadas, necessitamos de um mecanismo para limpar o sangue, e esse mecanismo seria provavelmente assegurado por glóbulos brancos. Descobriu-se que há um aumento do número de glóbulos brancos do sangue após o exercício. Nalguns casos aumentam até $140 \%$ após o exercício. Assim, depois de terminarmos o exercício, é quase como se estivéssemos infectados, como se houvesse uma inflamação num lugar do nosso corpo. De algum modo, os numerosos glóbulos brancos no plasma começam a limpar todo o lixo que foi produzido com os danos aos vários tecidos durante o exercício. Isto não é de maneira nenhuma surpreendente, isto é mesmo, de facto, o que se esperaria: se, quando terminamos o exercício e no dia seguinte, os tecidos estão realmente doridos, é porque provavelmente sofreram alguns danos e os glóbulos brancos responderam, entraram em acção e eliminaram alguns dos sistemas parcialmente danificados.

Ora isto era muito interessante, mas não era o que se veio a revelar o mais interessante. A «faísca» que se acendeu nessa altura foi algo um tanto diferente.

Eu sou um físico (ninguém é perfeito!) e isto significa que ao olhar para os problemas tento torná-los simples e reduzir o número das variáveis. A biologia tem muitas variáveis - ela é muito complicada - e, se tivermos um treino em física (e esta é a minha mensagem para os físicos), temos quase um compromisso moral de tentar reduzir os problemas ao nível mais 
simples possível, de modo que possam fazer não só descrições e testes como também previsões. Mas em sistemas complicados é muito difícil fazer previsões. É muito mais fácil se estivermos a lidar só com algumas variáveis. E qual foi a «faísca» que veio a certa altura? Eu estava muito preocupado porque queria encontrar uma maneira mais simples de medir os danos feitos em várias circunstâncias, quer durante o exercício, quer durante a gravidez ou a arteroesclerose. E qual se revelou o sistema mais agradável, mais elegante, mais simples para estudar os danos? Os glóbulos vermelhos do sangue! Porquê os glóbulos vermelhos? Primeiro porque há um grande número e um acesso muito fácil a eles; em segundo lugar, estão na «sopa» para onde vai toda a «sucata» para dentro e fora do sistema, de modo que estão em toda a parte do corpo; em terceiro lugar, e o mais importante, estas células não têm muitos mecanismos de reparação ou têm-nos em níveis muito baixos. Não há nenhum $\mathrm{ADN}$ nos glóbulos vermelhos humanos, de modo que não existe nenhuma síntese de novo das proteínas por exemplo. Assim, estas células são perfeitas para o nosso objectivo. Viajam por todo o corpo durante 120 dias e todos os danos que sofrem se acumulam lentamente. Se danificarem uma proteína específica, esses danos permanecem, não são reparados. Se ocorrerem mais danos mais tarde, eles acumulam-se. É como uma impressão digital: após 10, 60 ou 120 dias, um glóbulo vermelho colecciona todos os danos às suas proteínas. Com os lípidos é diferente: os lípidos são mais complicados porque são substituídos nos glóbulos vermelhos, e assim não se trata de um sistema muito bom para estudar. Mas um grande número dos danos que ocorrem nas proteínas não são reparados, sendo cumulativos. $\mathrm{E}$ foi isso que então nos decidimos a procurar.

Deixem-me sair agora da área do exercício e falar sobre alguns dos dados que temos na área da arteroesclerose.

O glóbulo vermelho do sangue tem uma forma engraçada: uma espécie de donut. Estes donuts são extraordinariamente flexíveis, podem mudar de forma muito facilmente. Têm uma estrutura muito, muito maleável. De facto, quando atravessam capilares adoptam as formas mais incríveis porque a membrana é um material muito elástico e, assim, um glóbulo vermelho consegue atravessar todos os capilares sem problema nenhum.

Mas uma das coisas que ocorrem enquanto os danos oxidativos são causados às proteínas é que estas se ligam umas às outras; as proteínas que estavam separadas ligam-se quando são oxidadas. E, à medida que ficam ligadas, à medida que ficam danificadas, os glóbulos vermelhos tornam-se menos flexíveis, não podem mover-se tão facilmente nos capilares, e, consequentemente, são provavelmente reconhecidos para serem removidos do sistema. 
Quantos dos presentes já fizeram análises ao sangue? Será que há alguém que nunca tivesse feito uma análise ao sangue? Está bem, todos fizeram... Quando trazemos para casa o relatório da análise, ele mostra muitas coisas: mostra a concentração de glóbulos vermelhos, de glóbulos brancos, de potássio, de cloro, de colesterol, de triglicéridos, de lipoproteínas de elevada densidade, de lipoproteínas de baixa densidade, etc. E todas as vezes que os valores estiverem um pouco desviados, tal aparece assinalado, de modo que podemos ver que os nossos valores estão desviados da norma, que já não são normais!

Há diversos parâmetros considerados factores de risco para acidentes cardiovasculares. Se tivermos colesterol elevado dizem-nos que o devemos vigiar, que devíamos comer mais fibras, frutas e vegetais e menos carne e gorduras. Infelizmente, o problema é que, frequentemente, estes parâmetros são contraditórios, e assim não são muito fiáveis. Uma pessoa pode ter o colesterol muito elevado e estar bem porque tem os níveis recomendados das lipoproteínas de densidade muito baixa. E os médicos estão sempre a discutir se é bom ter mais disto ou melhor mais daquilo... E agora há boas lipoproteínas de alta densidade e más lipoproteínas de alta densidade... Quero dizer, podemos ficar muito confusos. De vez em quando sai um artigo novo no Journal of the American Medical Association que diz que o colesterol afinal é bom! Desta maneira, podemos mesmo ficar muito confusos!

Assim, vamos ao médico e, no fim, ficamos sem ideia nenhuma sobre se devemos fazer isto, aquilo ou aqueloutro. Por isso, decidimos escolher populações que se sabe terem riscos acrescidos de acidentes cardiovasculares e olhar para os seus glóbulos vermelhos e brancos no sangue. E descobrimos que, à medida que o factor de risco aumenta (porque a população escolhida tem «o maior risco»), a proporção de neutrófilos, um tipo de glóbulos brancos, aumenta dramaticamente relativamente aos glóbulos vermelhos. Em alguns casos encontra-se um número de neutrófilos por eritrocitos mais de duas vezes superior ao que se encontra numa população de controlo (uma população com risco baixo).

O que dissemos então foi: Muito bem, temos mais glóbulos brancos; talvez eles estejam activados, talvez estejam a danificar as proteinas da membrana dos glóbulos vermelhos. Poderemos ver estes danos? Poderemos ver proteinas ligadas na membrana vermelha da célula? E olhámos para os agregados de uma proteína particular e descobrimos, para grande prazer nosso, que, de facto, o número de agregados da banda 3 (a proteína mais abundante na membrana de um glóbulo vermelho) é mais de $100 \%$ maior nas populações dos indivíduos com risco acrescido de acidentes cardiovasculares. Mas a mensagem aqui parece ser que, em 
todos os casos, quando se suspeita que têm um risco maior de um acidente desse tipo, têm mais agregados da banda 3 nos glóbulos vermelhos.

Há, de facto, uma evidência clara, mostrada há muitos anos, antes de eu ter começado a estudar o assunto, de que, à medida que as células envelhecem e ficam por isso mais danificadas, aumenta a agregação da banda 3. Mostrou-se que a agregação da banda 3 era o mecanismo inicial para o reconhecimento pelos macrófagos, que são as células que removem os glóbulos vermelhos do sangue quando estas ficam velhas e danificadas.

Assim, de facto, estávamos a ver nas pessoas com alto risco de arteroesclerose células mais danificadas, e provavelmente mais perto de serem removidas do sistema, do que nas pessoas saudáveis. E aquela é também uma razão por que os indivíduos de alto risco têm hematócritos, ou número total de glóbulos vermelhos, mais baixos que as pessoas normais. Por outro lado, previu-se que existia uma ligação da hemoglobina no interior da membrana do glóbulo vermelho. Quando a banda 3 se agrega, a hemoglobina liga-se à membrana e deixa de ser funcional; fica uma hemoglobina danificada, meta-hemoglobina. Esta ligação é conhecida dos médicos como o começo da formação de corpos de Heinz, quando os glóbulos vermelhos ficam cada vez mais danificados. Assim, procurámos a hemoglobina ligada na membrana e descobrimos, para nosso grande prazer, que a quantidade de hemoglobina ligada na membrana também aumentava de modo muito significativo para os três tipos de indivíduos com risco elevado nestas circunstâncias.

Assim, aqui têm: a arteroesclerose, que é muito difícil de detectar porque é uma inflamação de nível baixo, contínua, torna-se fácil de detectar nos glóbulos vermelhos do sangue porque nestes tudo se acumula, tanto fazendo que se trate de nível baixo como não. Se a inflamação for de nível baixo, mas a célula em observação se conseguir reparar, não podemos observar os danos; se for de nível baixo, mas uma célula não se reparar, os danos acumulam-se lentamente e podemos vê-los. Os danos que se acumulam ao longo de muitas semanas ou meses nos glóbulos vermelhos dos pacientes não são reparados porque os glóbulos vermelhos têm sistemas de reparação limitados (não têm nenhum núcleo!). Assim, acumulam-se e podem facilmente ser detectados.

Deixem-me agora chegar ao final, que é... Eu tenho de mostrar o seguinte: a teoria de que os glóbulos brancos danificam os glóbulos vermelhos in vivo é bonita, mas como provar que é verdadeira? Bem, isolamos os glóbulos brancos, pômo-los in vitro com glóbulos vermelhos, activamos os glóbulos brancos e vemos se se obtêm o mesmo tipo de danos. De outra maneira o que temos não passa de wishful thinking. 
Assim, quando o fazemos e em seguida examinamos glóbulos vermelhos com números crescentes de neutrófilos, obtemos quantidades crescentes de agregados de banda 3 no sistema. Deste modo, podemos reproduzir, in vitro, a agregação da banda 3 que vemos in vivo. Portanto, não era wishful thinking.

Apenas quero ainda acrescentar que estas alterações à membrana - esta história da agregação de proteínas, o facto de também os lípidos se danificarem e o glóbulo vermelho mudar de forma - podem ser modeladas considerando as características físicas da membrana do glóbulo vermelho. Não apresento os pormenores, mas conto-vos o que fizemos há alguns anos. A membrana do glóbulo vermelho é uma bicamada de lípidos conectados ao cito esqueleto que mantém no sítio todas as proteínas da membrana. As células velhas começam a ficar espiculadas, começam a ficar com espículos pequenos que aparecem por todo o lado. Podemos desenvolver um modelo físico descrevendo o estado de elasticidade da membrana por um conjunto de equações que incluem a energia elástica da membrana, a sua energia de dobra, a interação entre componentes diferentes (lípidos e proteínas) na membrana, a variação da entropia do sistema, e ainda um termo muito pequeno que tem a ver com o facto de, nestes espículos pequenos, o esticamento não ser linear do ponto de vista físico (exige derivadas de segunda ordem). Tomamos tudo isso como a energia da célula e minimizamo-la relativamente à concentração das proteínas danificadas. Podemos então prever o número dos espículos que vão ocorrer numa célula, num glóbulo vermelho, e não apenas isso, mas também que, quando ela começa a ficar com demasiados espículos, estes são empurrados para fora da membrana. Obtém-se a vesiculação: a membrana encurva tanto que acaba por se fundir consigo própria e um bocadinho da membrana é removido. Isto é bem sabido dos hematologistas: quando começam a ficar velhas e danificadas, as células ficam menores porque perdem a membrana. Nós modelámos o mecanismo de perda da membrana. Quando fizemos os cálculos no computador, descobrimos que, em determinadas condições de danos extensos à membrana do glóbulo vermelho, há duas soluções para a curvatura da membrana: uma que é a célula grande que permanece atrás e outra que é o novo vesículo pequeno, que veio de fora.

Assim (este é o sítio onde entra a física!), podemos realmente escrever a expressão para a energia do sistema, minimizá-la de modo a descrever o equilíbrio, e encontrar a solução que prevê a vesiculação da membrana para certas quantidades de danos feitos à proteína ou ao lípido. Como é fácil imaginar, para um físico como eu, que teve a sorte de ter «rançado» e de se ter transformado em biólogo, tudo isto é muito emocionante. 
Depois de ter feito toda a biologia e ter recolhido os dados, pude voltar atrás, recordar-me de um pouco da física que tinha feito, e descobrir uma solução para o problema que previa a vesiculação da membrana.

Este trabalho resultou de uma colaboração interessante. Fiz o meu doutoramento em Joanesburgo, na África do Sul, com um físico descendente de judeus portugueses que emigraram para Inglaterra. Chama-se Nabarro. Alguns anos mais tarde, ele disse-me: também quero aprender um pouco de biologia, de modo que veio a Berkeley e eu supervisionei-o. $\mathrm{O}$ nosso artigo foi publicado há alguns anos. Ken Hanson, um engenheiro muito hábil, fez todo o trabalho computacional, fornecendo-nos muitas e bonitas simulações em forma gráfica que nos ajudaram a compreender os modelos físicos que desenvolvemos.

Claro que poderia gastar muito mais tempo a falar sobre isto, mas quis fazer uma descrição do que começa por ser um sistema essencialmente sujo, que é, como sabem, o exercício. O exercício é sujo: suamos por todos os poros, cheiramos mal e há todo o tipo de coisas no exercício. A arteroesclerose é também muito complicada. Mas podemos lentamente (talvez este seja o ponto onde a física ajuda...) encontrar maneiras de simplificar o problema, fazendo perguntas simples e desenvolvendo os modelos simples que fazem previsões passíveis de teste.

Assim, olhámos em primeiro lugar para os glóbulos brancos e vimos que o seu número aumentava. Depois descobrimos que alguns glóbulos brancos (neutrófilos) ficam activados. Então decidimos que o glóbulo vermelho devia ser um bonito marcador para este fenómeno, e acabámos por descobrir que era. Trata-se de um sistema simples de usar. E, finalmente, uma vez que o glóbulo vermelho é bonito e simples, podemos realmente modelá-lo por um sistema físico esquemático e escrever uma expressão para a energia da membrana. Se minimizarmos a energia para descrever o equilíbrio, encontramos uma solução que prevê exactamente o que vemos no nosso sistema.

A minha mensagem final é: quem quiser algum dia ir da física para a biologia primeiro tem de aprender muita biologia, tem de sujar as mãos com todo o género de coisas (células grandes, organismos, sistemas complicados, etc.), e, por favor, nunca esquecendo que o importante é conseguir simplificar suficientemente a descrição de modo a permitir efectuar previsões. A física pode ajudar: escreve-se uma equação elegante e depois é só minimizar... e pronto! Prevê-se o comportamento do sistema real. Os físicos conseguem realmente fazê-lo e é por isso que, por vezes, são acusados de serem um pouco arrogantes. 
(Página deixada propositadamente em branco) 
 \\ A palavra "fronteiras" pode ser tomada em} diferentes sentidos. Pode referir-se aos limites, necessariamente provisórios, entre o conhecido e o desconhecido, ou aos limites entre o possivel e o impossivel, e, dentro do possivel, entre o desejável e 0 indesejável. Fronteiras podem também ser as delimitações, nem sempre nítidas, entre ciência e não-ciência, e dentro da ciência, entre as várias disciplinas. Quais são então as fronteiras da ciência?

Neste livro, a resposta a esta pergunta é dada, segundo as mais diferentes perspectivas, por um conjunto notável de personalidades, cientistas ou não, entre as quais se contam três Prémios Nobel.

Rui Fausto, Carlos fiolhais e JoÃo Fillipe Queiró são, respectivamente, professores de Química, Física e Matemática na Faculdade de Ciências e Tecnologia da Universidade de Coimbra. 